\title{
Estimating Abundance of Reef-Dwelling Sharks: A Case Study of the Epaulette Shark, Hemiscyllium ocellatum (Elasmobranchii: Hemiscyllidae) ${ }^{1}$
}

\author{
M. R. Heupel ${ }^{2,3}$ and M. B. Bennett ${ }^{2}$
}

\begin{abstract}
Benthic reef sharks play an important role in reef ecosystems, but little is known about their abundance or population dynamics. Abundance of the epaulette shark, Hemiscyllium ocellatum (Bonnaterre), on Heron Island Reef, Great Barrier Reef, Australia, was examined via a mark-recapture study. A total of 496 sharks was tagged between July 1994 and August 1997 in a $0.25-\mathrm{km}^{2}$ area of reef flat, with 80 tagged sharks recaptured for a total of 102 recapture events. Captured individuals ranged in size from juveniles to adults $(285-750 \mathrm{~mm}$ total length). Recaptured sharks were collected after 1-725 days at liberty and at distances of $0-329 \mathrm{~m}$ from their original capture point. The overall recapture rate was $20.6 \%$ with an estimated $17.5 \%$ tag loss. Population size was estimated using both closed and open population models. Closed population models produced various abundance estimates, with the Chao $M_{(t h)}$ ranked best in model performance with an estimate of 2,224 sharks and $95 \%$ confidence intervals ranging from 1,730 to 2,916. Open population models produced lower estimates, with the Jolly D model producing an estimate of 559 individuals within the study site and confidence intervals ranging from 26 to 1,092. All models produced density estimations of 0.3 to 1.2 sharks per $100 \mathrm{~m}^{2}$. Based on thorough examination of model assumptions and results, open population models appear to provide the best population estimate within the study area.
\end{abstract}

LitTLE INFORMATION is currently available concerning the life history, distribution, and movements of many benthic shark species.

\footnotetext{
${ }^{1}$ Work was supported by grants from The Great Barrier Reef Marine Park Authority and The Australian Coral Reef Society and was undertaken while M. R. Heupel was in receipt of an Overseas Postgraduate Research Scholarship at the University of Queensland, Australia. Work was conducted under QFMA permit numbers 6435 and PRM00080I and GBRMPA permit numbers G95/454 and G95/595. Manuscript accepted 14 August 2006.

${ }^{2}$ School of Biomedical Sciences, Department of Anatomy and Developmental Biology, The University of Queensland, St. Lucia, Queensland, Australia 4072.

${ }^{3}$ Author to whom correspondence should be addressed. Current address: Center for Shark Research, Mote Marine Laboratory, 1600 Ken Thompson Parkway, Sarasota, Florida 34236 (phone: 941-388-4441; fax: 941-388-4312; e-mail: mheupel@mote.org).
}

Pacific Science (2007), vol. 61, no. 3:383-394 (C) 2007 by University of Hawai'i Press

All rights reserved
This is especially true for reef-dwelling species that can be difficult to observe and capture. Understanding the life history and population dynamics of these species is becoming increasingly important because of their use in the aquarium trade and the current decline of many reef systems around the world due to human impacts, environmental changes, and fishing pressures (e.g., McManus 1997, Souter and Linden 2000, Szmant 2002, Goldberg and Wilkinson 2004). Species such as the epaulette shark, Hemiscyllium ocellatum (Bonnaterre), are important predators on the reef flat, feeding predominantly on benthic invertebrates (Heupel and Bennett 1998). Understanding the movement patterns and population size of this species may lead to insight into ecological linkages within coral reef systems.

Standard mark-recapture methods have been used extensively to estimate population sizes and gross movement patterns of sharks. However, most of these studies were completed in conjunction with fisheries research, 
allowing large numbers of individuals to be tagged and released (e.g., Olsen 1953, Casey et al. 1985, Stevens 1990, Casey and Kohler 1992). Although this approach has the potential for a high number of recaptures via fishing fleets, recapture rates are still generally low. It is not uncommon for elasmobranch population studies to have recapture rates below 10\%. The National Marine Fisheries Service Cooperative Shark Tagging Program has targeted large sharks in the North Atlantic, with more than 171,000 sharks of 52 species tagged between 1962 and 2001, and just over 10,000 sharks of 33 species recaptured (Kohler and Turner 2001). Of 4,695 school sharks (Galeorbinus galeus) tagged over $6 \mathrm{yr}$ in southeastern Australia, only 4\% were recaptured (Olsen 1953), and of 2,459 shortfin mako sharks, Isurus oxyrinchus, tagged over a 28 -yr period in the western North Atlantic, 9\% were recaptured (Casey and Kohler 1992). It has typically been difficult to produce catch rates high enough to produce reliable population estimates for many shark species without a large-scale project involving many people or a fishery to help recover tags.

Population estimators are subject to a number of assumptions that must be considered when defining the study population. Researchers have the choice of using open or closed population models. Open population estimators allow for immigration, emigration, birth, and death within the target population and are typically used in long-term studies. Closed population estimators assume there is no net change within the population and therefore individuals do not move into or out of the population. This analysis is usually used in short-term studies (Lebreton et al. 1992). A wide array of population estimators is available for analysis of mark-recapture data sets for both open and closed populations (Begon 1979).

In this study we aimed to calculate one of the first total population estimates for a small reef-dwelling shark, Hemiscyllium ocellatum, within a tropical coral reef platform utilizing mark-recapture data. The epaulette shark, classed by Compagno (1990) as leptobenthic, is endemic to Australia and New Guinea. Leptobenthic species typically rest on the bottom, hiding in crevices in rocks and coral during the day, becoming active at night. Little is known about the size of their activity space or their long-term movements. Understanding the abundance and distribution patterns of benthic sharks helps define the functioning of reef ecosystems.

\section{MATERIALS AND METHODS}

Hemiscyllium ocellatum was captured by hand netting from a $0.25-\mathrm{km}^{2}$ study site on Heron Island Reef, Great Barrier Reef, Australia $\left(23^{\circ} 27^{\prime} \mathrm{S}, 151^{\circ} 55^{\prime} \mathrm{E}\right)$ (Figure 1). Individual sharks were tagged and released over a 4-yr period within the study site. This species is born at a small size, sexual maturity is reached after approximately $4 \mathrm{yr}$ (ca. $55 \mathrm{~cm}$ total length [TL]), and individuals appear to live for at least $6 \mathrm{yr}$ (M.R.H., unpubl. data). The life history of $H$. ocellatum provided an opportunity to apply both open and closed population estimators to this data set and allowed pooling of mark-recapture data through the duration of the project.

Eleven sampling trips were conducted for mark-recapture studies between July 1994 and August 1997 (see Table 1). Each of the 11 trips included an average of 14 days of sampling (range: 7-24, mode: 18 days). The average length of time between sampling trips was 93 days (range: 49-96). Sharks were captured during reef walks conducted within $2 \mathrm{hr}$ of low tide. A single observer walked transects that provided complete coverage of the study site, with daytime transects running parallel to the beach and nighttime transects running perpendicular to the beach. One day and one night survey were conducted per sampling day. During each set of daily surveys the entire study area was sampled. Sampling period was approximately $3 \mathrm{hr}$ per survey. Transects were run in different directions during the day and night to ensure coverage of the study area and to prevent double sampling by walking the same transect lines during the same day. An equal number of transects were walked during day and night surveys and were conducted in a wide range of weather conditions. Due to the cryptic nature of this species and the necessity of walk- 


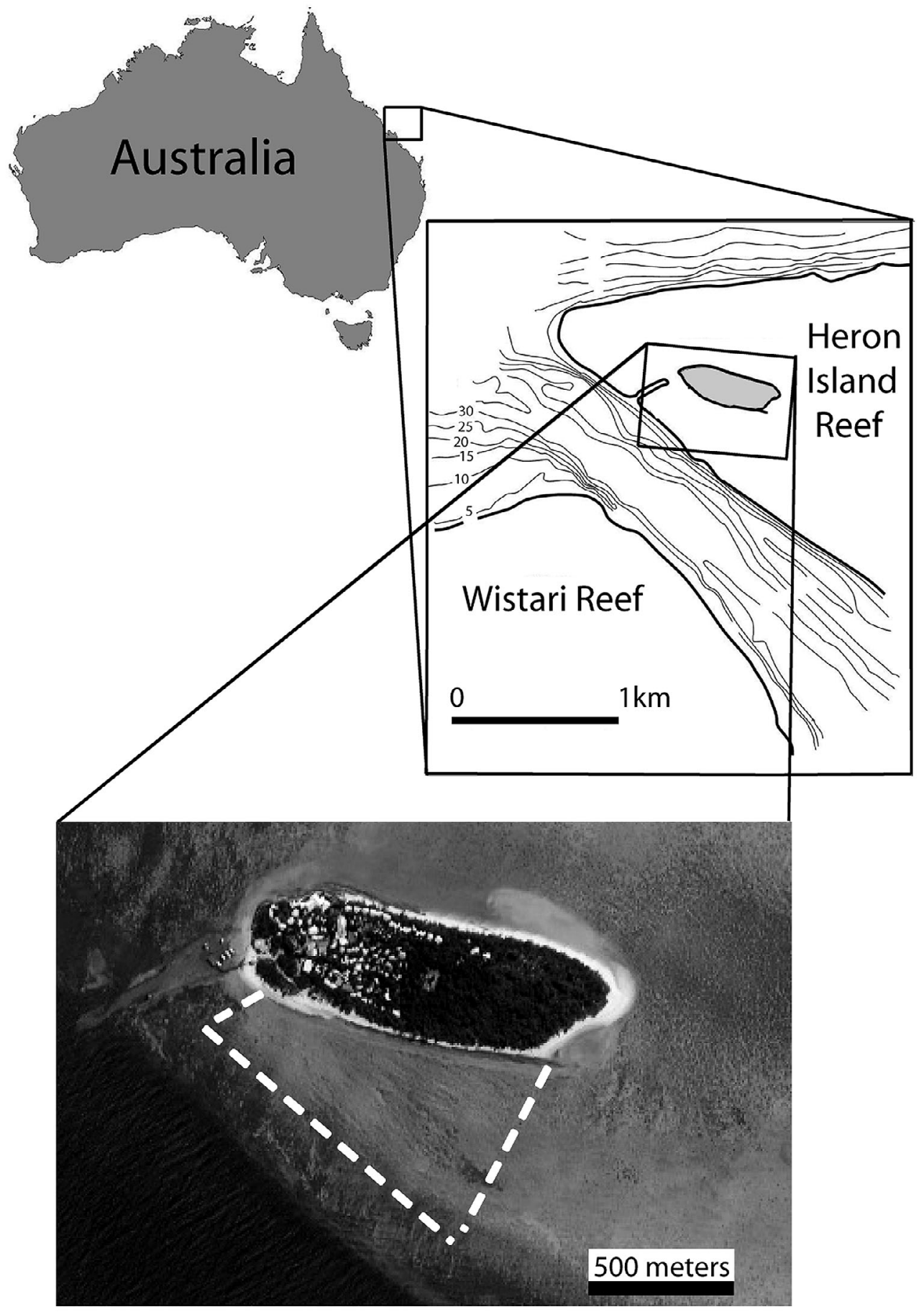

FigURE 1. Location of Heron Island, Great Barrier Reef, with aerial photograph showing the study area, delineated by the dotted lines, lying between the southern shore and the reef crest. 
ing around coral outcroppings line transect data could not be used to estimate shark density. As a proxy for this we examined the number of sharks collected per year divided by the number of sampling events (individual reef walks) per year to produce an estimate of annual catch per reef walk.

Captured sharks were measured to the nearest centimeter (TL), weighed to the nearest $5 \mathrm{~g}$, sexed, and tagged with a numbered, single-barb dart tag (Hallprint, Australia) at the base of the first dorsal fin. All animals were released at the point of capture. After release, the capture location was recorded by taking hand-bearing compass bearings on a minimum of three, previously determined, fixed points of reference. All reference points were visible at night due to lights on the reference point itself or lights from the research station. The locations of reference points were plotted on a scale map of the study site, allowing the capture site to be calculated by triangulation. Recapture locations were similarly determined using compass bearings.

Tag loss was estimated by examining captured sharks for tag scars, partial tags that had broken or been eroded, or illegible tags. Scars resulting from a shed tag were obvious and easily identifiable (Heupel and Bennett 1997). All scarred animals were noted in tag records and retagged. The ratio of scarred sharks to the total number of sharks recaptured was used to estimate the proportion of tag loss.

Both open and closed population estimators were used to analyze $H$. ocellatum markrecapture data (Begon 1979). Closed population estimates and standard errors were calculated using maximum likelihood methods. Estimates were made using the computer program Capture (White et al. 1978) run as a subroutine within Program Mark (White and Burnham 1999). Six different estimators were used: one with constant probability of capture $\left(\mathrm{Null}_{\mathrm{O}} \mathrm{M}_{(\mathrm{o})}\right)$, two with individually varying capture probability (Chao and Jackknife $\left.M_{(\mathrm{h})}\right)$, two with time-specific capture probabilities (Chao and Darroch $M_{(\mathrm{t})}$ ), and one with individually and time-specific capture probabilities $\left(\right.$ Chao $\left.\mathrm{M}_{(\mathrm{th})}\right)$. These six esti- mators are a subset of those available within Program Capture and allowed different assumptions about the catchability of individuals to be assessed and the most appropriate estimator to be selected. Other estimators not appropriate to the type of data collected in this study were excluded from consideration. The Program Capture routine Appropriate was used to rank each of these six estimators. The Appropriate routine uses a series of seven goodness of fit tests to evaluate the assumptions associated with each model. The results of these tests are then used in a 16-parameter multivariate discriminant function analysis to rank models (Otis et al. 1978). Open population estimates were derived based on the Jolly-Seber approach using the computer program Jolly (Pollock et al. 1990). Three formulations of the Jolly-Seber model were evaluated: (1) time-specific estimates of survival and immigration (Jolly A), (2) timespecific survival but no immigration (Jolly $\mathrm{A}^{\prime}$ ), and (3) constant survival and capture probability (Jolly D).

The Jolly-Seber models have several assumptions that must be met by the sample population. This method requires that: (1) tags are permanent and their codes are identified correctly upon recapture, (2) every individual has the same probability of capture, regardless of whether it is tagged or not, (3) every individual has the same probability of survival, regardless of whether it is tagged or not, (4) emigration is permanent, and (5) sampling time is short compared with the interval between samples (Krebs 1989, Fitz and Weigert 1992).

RESULTS

\section{Tag Data}

During the course of this study 496 sharks (251 male, 245 female) were collected and fitted with tags during the 11 sampling trips. Annual catch rates based on the number of sharks collected and the number of sampling events conducted revealed a decreasing trend in number of sharks captured. Highest catch rate occurred in 1994 (3.9 sharks per sample) with a slight decrease in 1995 (3.5 sharks per 
TABLE 1

Summary of Tag-Release Data and Recapture Percentages for H. ocellatum by Sampling Trip and Cumulatively

\begin{tabular}{|c|c|c|c|c|c|c|}
\hline Trip & Month & $\begin{array}{c}\text { No. } \\
\text { Tagged } \\
\text { per Trip }\end{array}$ & $\begin{array}{l}\text { Total } \\
\text { No. } \\
\text { Tagged }\end{array}$ & $\begin{array}{c}\text { No. } \\
\text { Recaptured } \\
\text { by Trip }\end{array}$ & $\begin{array}{c}\text { Total } \\
\text { No. of } \\
\text { Recaptures }\end{array}$ & $\begin{array}{c}\text { Size } \\
\text { Range }\end{array}$ \\
\hline 1 & Jul. 1994 & 20 & 20 & - & - & $\begin{array}{l}500-710 \\
(660)\end{array}$ \\
\hline 2 & Nov. 1994 & 27 & 47 & 0 & 0 & $\begin{array}{l}560-740 \\
(660)\end{array}$ \\
\hline 3 & Jan.-Feb. 1995 & 101 & 148 & $\begin{array}{l}8 \\
(7.9 \%)\end{array}$ & $\begin{array}{l}8 \\
(5.4 \%)\end{array}$ & $\begin{array}{l}480-740 \\
(640)\end{array}$ \\
\hline 4 & Apr. 1995 & 34 & 182 & $\begin{array}{c}7 \\
(20.6 \%)\end{array}$ & $\begin{array}{l}15 \\
(8.2 \%)\end{array}$ & $\begin{array}{l}410-750 \\
(620)\end{array}$ \\
\hline 5 & Nov. 1995 & 72 & 254 & $\begin{array}{c}12 \\
(16.7 \%)\end{array}$ & $\begin{array}{l}27 \\
(10.6 \%)\end{array}$ & $\begin{array}{l}500-750 \\
(640)\end{array}$ \\
\hline 6 & Feb.-Mar. 1996 & 31 & 285 & $\begin{array}{c}7 \\
(22.6 \%)\end{array}$ & $\begin{array}{l}34 \\
(11.9 \%)\end{array}$ & $\begin{array}{l}350-740 \\
(580)\end{array}$ \\
\hline 7 & Jun.-Jul. 1996 & 47 & 332 & $\begin{array}{c}9 \\
(19.1 \%)\end{array}$ & $\begin{array}{l}43 \\
(13.0 \%)\end{array}$ & $\begin{array}{l}340-720 \\
(590)\end{array}$ \\
\hline 8 & Sept.-Oct. 1996 & 66 & 398 & $\begin{array}{l}21 \\
(31.8 \%)\end{array}$ & $\begin{array}{l}64 \\
(16.1 \%)\end{array}$ & $\begin{array}{l}370-750 \\
(610)\end{array}$ \\
\hline 9 & Nov.-Dec. 1996 & 67 & 465 & $\begin{array}{l}25 \\
(37.3 \%)\end{array}$ & $\begin{array}{l}89 \\
(19.1 \%)\end{array}$ & $\begin{array}{l}290-730 \\
(590)\end{array}$ \\
\hline 10 & Apr.-May 1997 & 15 & 481 & $\begin{array}{c}6 \\
(40.0 \%)\end{array}$ & $\begin{array}{l}95 \\
(19.8 \%)\end{array}$ & $\begin{array}{l}310-500 \\
(420)\end{array}$ \\
\hline 11 & Aug. 1997 & 14 & 496 & $\begin{array}{c}2 \\
(14.3 \%)\end{array}$ & $\begin{array}{l}97 \\
(19.6 \%)\end{array}$ & $\begin{array}{l}420-650 \\
(500)\end{array}$ \\
\hline
\end{tabular}

Note: Length ranges and mean size (in parentheses) of individuals collected on each trip are included.

sample) and a continued decline in 1996 (2.8 sharks per sample) and 1997 (1.0 sharks per sample).

Sharks ranged in size from 285 to $750 \mathrm{~mm}$ TL. Size ranges for males and females were similar, with males from 285 to $750 \mathrm{~mm}$ TL (mean: $612 \mathrm{~mm}$ TL) and females from 310 to $750 \mathrm{~mm}$ TL (mean: $605 \mathrm{~mm}$ TL). Both males and females were considered mature at sizes over $550 \mathrm{~mm}$ TL as defined by Heupel et al. (1999). There were no changes in sex ratios of captured sharks over time, and sex ratios were not significantly different from $1: 1$ (chi-square test, $\mathrm{X}^{2}=0.075, \mathrm{df}=1, P=$ .785 ). The number of individuals caught per trip varied and the average size of individuals captured decreased through time with greater numbers of juvenile sharks collected in later sampling trips (Table 1). The relationship between length and mass of captured individuals was weight $=0.014$ (total length) $)^{1.654}$ $\left(r^{2}=0.993, n=496, P<.001\right)$.

In 1994 the majority of sharks collected ranged from 480 to $740 \mathrm{~mm}$ TL. In 1995 collected individuals varied in size and increased the size range from 400 to $750 \mathrm{~mm}$ TL. No individuals larger than $750 \mathrm{~mm}$ TL were collected. During 1996 an increased number of small sharks were captured including collection of the smallest individual within the study $(285 \mathrm{~mm}$ TL). This pattern of collecting smaller individuals through time may have been the result of increased experience in animal spotting and collection. However, in 1997 the majority of the catch consisted of juvenile sharks less than $500 \mathrm{~mm} \mathrm{TL}$ (Figure 2).

\section{Recaptures}

A total of 97 sharks was recaptured, but 17 individuals had scars due to tag loss or partial tags that could not be read. These individuals were excluded from population analyses because data concerning the initial tagging event were unknown, leaving 80 individuals 

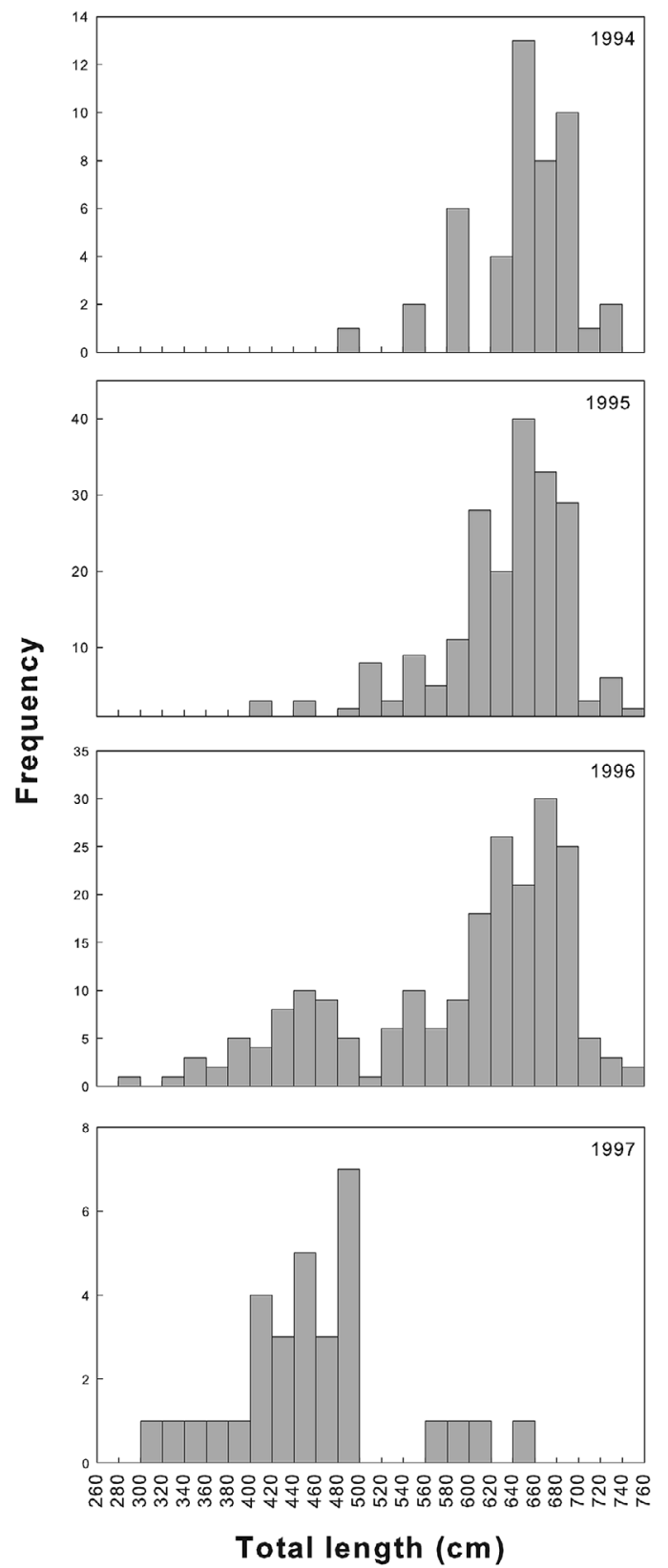

Figure 2. Length frequency of Hemiscyllium ocellatum collected on Heron Island Reef displayed by year of capture. for further analyses. Total tag loss throughout the study was estimated to be $17.5 \%$. The remaining 80 sharks with intact tags were recaptured for a total of 102 recapture events (20.6\%). Recapture rates among and across trips varied through time (Table 1). Of the 80 recaptured individuals, one was recaptured four times, two were recaptured three times, and 15 were recaptured twice. The remaining 62 individuals were only recaptured once. Many of the tags on recaptured individuals were significantly damaged, and six individuals were retagged.

The size composition of recaptured sharks was similar to that of the tagged population. Recaptured male sharks ranged in size from 510 to $720 \mathrm{~mm}$ TL (mean: 648) and females ranged from 430 to 730 TL (mean: 636). Almost equal numbers of males (36) and females (44) were recaptured during the study period $\left(\mathrm{X}^{2}=0.813, P=0.367\right)$.

The average distance between release and recapture of all individuals was $84 \mathrm{~m}$ (standard error $=7 \mathrm{~m}$ ). The shortest distance moved by an individual was $0 \mathrm{~m}$. Two individuals were captured close enough to their location of original recapture to be considered to have no net movement. The greatest net distance moved by an individual was 329 $\mathrm{m}$ (Figure 3). Most individuals traveled 30$49 \mathrm{~m}$ between the time of original release and recapture. Recaptured sharks were at liberty for periods of 1-725 days (Figure 4). The majority of sharks were recaptured within 1 to 50 days of release and many were recaptured within the same sampling trip (although not on the same day as tagging). Distance traveled was not dependent on time at liberty $\left(r^{2}=0.610\right.$, slope $=-0.007, n=80$, $P=.848)$ or shark size $\left(r^{2}=0.585\right.$, slope $=$ $0.062, n=80, P=.197)$. There was no significant difference in distance moved between individuals recaptured during the day or night $(t$-test, $t=1.993, \mathrm{df}=74, P=.396)$.

\section{Population Size}

Population estimates were calculated assuming both a closed and an open population system. Closed population estimates resulted in total population sizes ranging from 1,814 to 


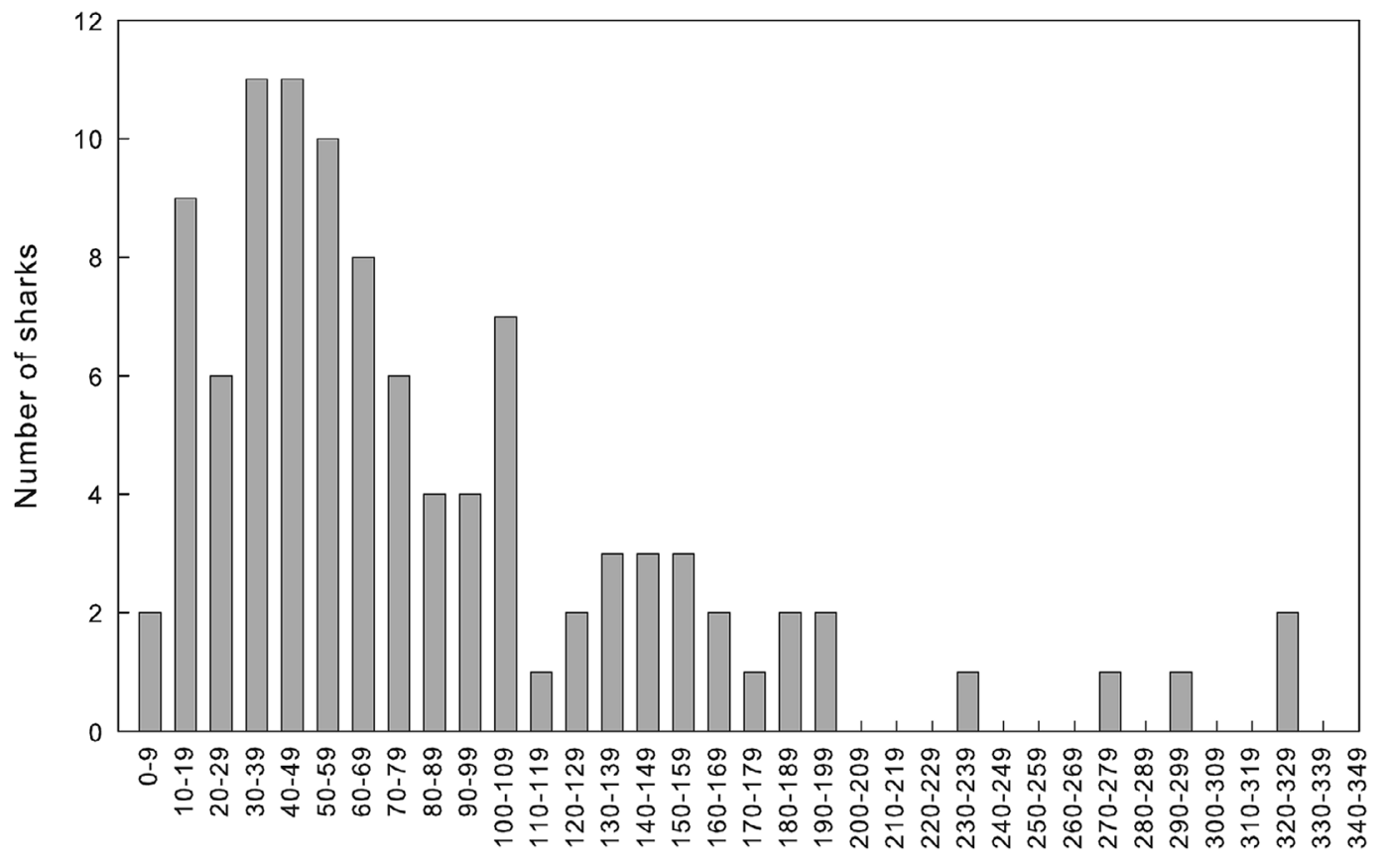

\section{Distance moved $(\mathrm{m})$}

FIGURE 3. Distances moved by 80 sharks for 102 recapture events within the study site. Distances represent a straightline movement from the point of initial capture to the point of recapture. In instances of multiple recaptures measures were taken from the point of first recapture to the point of the second recapture.

2,249 sharks within the study site. The Chao $\mathrm{M}_{\text {(th) }}$ estimator (time and individual variability in capture probability) was ranked the highest by the model selection procedure and estimated the population size to be 2,224 with a standard error of 299.3 (Table 2). The two estimators with time-specific capture probabilities (Darroch $\mathrm{M}_{(\mathrm{t})}$ and Chao $\mathrm{M}_{(\mathrm{t})}$ ) also ranked highly but produced slightly lower values of population size. Open population estimates showed greater variability in population size than those from closed models. Population estimates from the three JollySeber models ranged from 553 to 1,905 individuals (Table 3). Model Jolly A did not produce standard error or confidence interval estimates because there were no recaptures in the first two sampling periods, but both models Jolly A' and Jolly D did. To overcome the lack of confidence intervals for the Jolly A model it was rerun without the first period, producing a population estimate of 553 and a $95 \%$ confidence interval of 151-957. The Jolly A and D models produced very similar estimates, but the Jolly $\mathrm{A}^{\prime}$ produced a higher value. All three Jolly models produced large differences in the mean population estimate $(N)$, but confidence intervals for the three overlapped.

Although Jolly A and Jolly D estimates agreed, they were not similar to results produced by closed population estimates. Estimates produced by Jolly $\mathrm{A}^{\prime}$ overlapped with those by Jolly A and Jolly D but were in closer agreement with closed population estimates. Examination of the number of sharks 


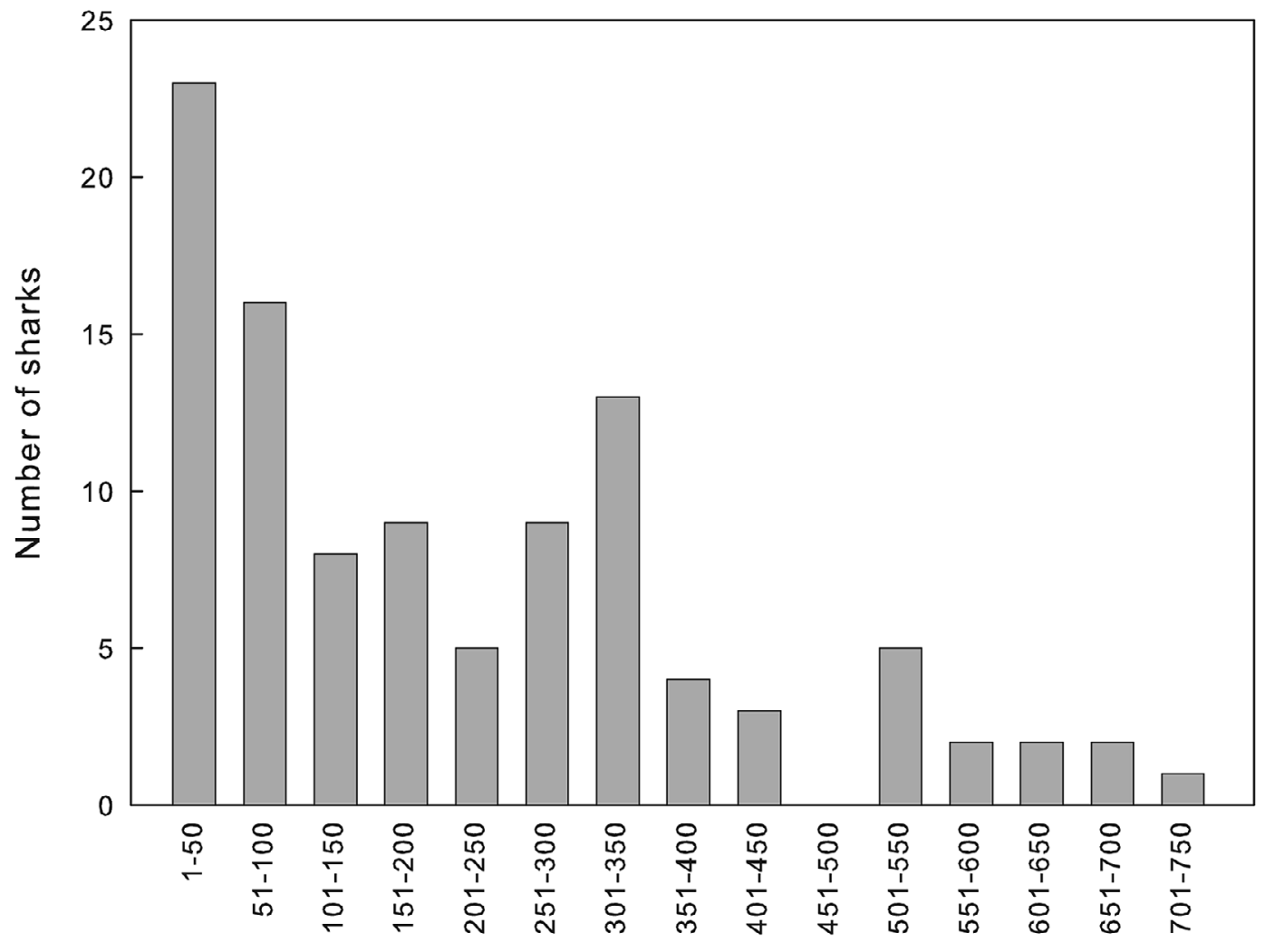

\section{Days at liberty}

FigURE 4. Frequency distribution of the number of days at liberty for 102 recapture events of Hemiscyllium ocellatum on Heron Island Reef.

TABLE 2

Population Estimates for Hemiscyllium ocellatum within the Study Site on Heron Island Reef Showing Estimates Based on a Closed Population Including Standard Error and $95 \%$ Confidence Intervals

\begin{tabular}{|c|c|c|c|c|}
\hline Estimators & Rank & $N$ & $\begin{array}{l}\text { Standard } \\
\text { Error }\end{array}$ & $95 \%$ CI \\
\hline Chao $M_{\text {(th) }}$ & 1.00 & 2,224 & 299.3 & $1,730-2,916$ \\
\hline Darroch $M_{(t)}$ & 0.89 & 1,825 & 190.5 & $1,503-2,266$ \\
\hline Chao $M_{(t)}$ & 0.89 & 2,009 & 253.3 & $1,588-2,591$ \\
\hline Null $M_{(o)}$ & 0.13 & 1,880 & 198.0 & $1,544-2,326$ \\
\hline Jackknife $M_{(\mathrm{h})}$ & 0.09 & 1,814 & 92.6 & $1,645-2,008$ \\
\hline Chao $M_{(\mathrm{h})}$ & 0.09 & 2,249 & 294.7 & $1,760-2,927$ \\
\hline
\end{tabular}

TABLE 3

Jolly-Seber Population Estimates for Hemiscyllium ocellatum within the Study Site on Heron Island Reef

Showing Estimates Based on an Open Population Including Standard Error and 95\% Confidence Intervals

\begin{tabular}{lccc}
\hline \hline Model & $N$ & $\begin{array}{c}\text { Standard } \\
\text { Error }\end{array}$ & $95 \%$ CI \\
\hline A & 553 & - & $151-957$ \\
A $^{\prime}$ & 1,905 & 555 & $816-2,994$ \\
D & 559 & 272 & $26^{a}-1,092$ \\
\hline \multicolumn{4}{c}{${ }^{a}$ Actual population was at least 80 individuals. }
\end{tabular}




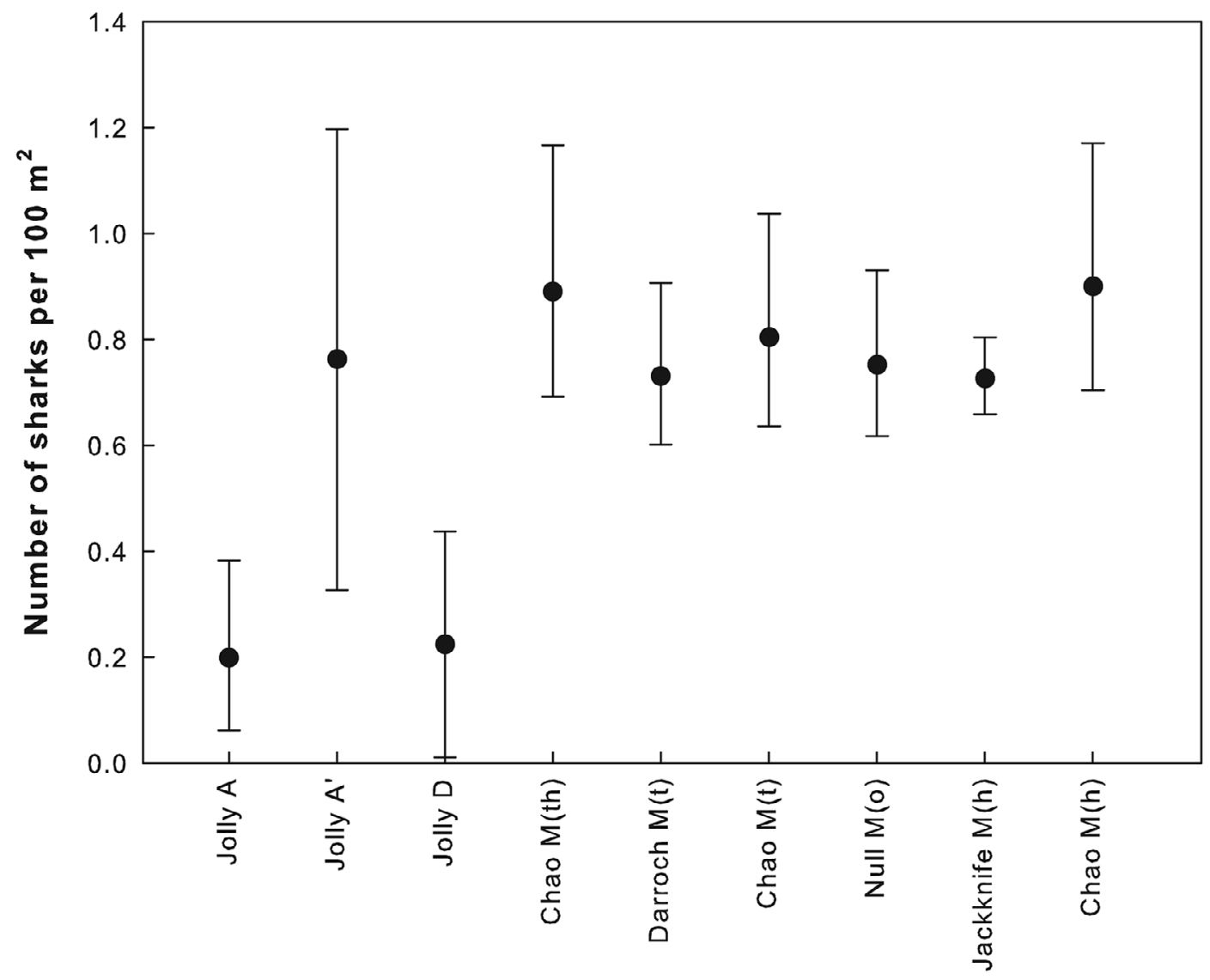

\section{Estimator}

FiguRE 5. Density of Hemiscyllium ocellatum within the study site calculated from open and closed population models. Estimates are for a $250,000-\mathrm{m}^{2}$ study area. Bars indicate confidence intervals calculated by models.

present per $100 \mathrm{~m}^{2}$ within the study site based on population estimators displays the differences in population estimates among models (Figure 5). Seven of the nine models tested resulted in population estimates ranging between 0.3 to 1.2 sharks per $100 \mathrm{~m}^{2}$, with six models (all six closed population models) estimating population densities between 0.6 to 1.2 sharks per $100 \mathrm{~m}^{2}$.

\section{DISCUSSION}

Results of this research show that markrecapture studies can be effective and provide viable abundance estimates for cryptic reef shark populations. Mark-recapture efforts suggest that a large proportion of the population was sampled based on a relatively high recapture rate for a shark population. Large numbers of recaptures suggest that individuals may be resident within the study site. This result is similar to findings for other benthic elasmobranchs. For example, Standora and Nelson (1977) used acoustic tracking to relocate Pacific Angel sharks (Squatina californica) and found most individuals near their location of original tagging. These results suggest that benthic elasmobranchs may 
show a high degree of site fidelity. Multiple recaptures of the same individual suggest that individuals were still resident within the region and available for recapture within the study site. Recapture rates and the presence of multiple recaptures also suggest that sharks did not avoid capture. A large number of single recapture events revealed that individuals did not become "trap-happy" and thus more prone to capture than untagged individuals. Therefore the capture of sharks within the study site should be representative of the available population.

Although catchability was not affected by tagging, other factors played a role in locating individuals for capture. Due to the nocturnal nature of this species it was often easier to spot individuals during night sampling or on cloudy or overcast days. Under these lower light conditions sharks were more likely to be observed outside coral cover and therefore were easier to locate and capture. Experience level was also a factor in shark detection. Examination of the size of individuals caught per year displays an increased aptitude for locating and collecting smaller individuals as the study progressed. For example, location of a small individual in a coral head (rather than under a coral head or exposed on the sand) provided valuable information for searching for small individuals in the future. Although these factors were present, population models are designed to handle variability in catchability and therefore it was not a factor in overall model performance and abundance estimates.

Although increasing numbers of juvenile sharks were collected in the later years of the project, researcher experience cannot explain the catch size composition in 1997. Greater experience by the surveyor would not have precluded the capture of the larger-sized adults that dominated the catch in previous years. Similarly, there were no changes in the sampling effort or methodology that can account for the decreased number of sharks per sampling event in 1997 compared with previous years. Thus it appears from these data that a decline in the number of adult sharks present had occurred. The cause of this decline is difficult to define but may be related to harvesting for research. A total of 75 juvenile and adult sharks was removed over a period of $4 \mathrm{yr}$ during the course of this research effort. Due to the proximity of this site to the research station additional research teams also collected animals from this region. Because juvenile animals could be difficult to locate it is likely that these teams collected adult sharks. The number of individuals taken by other research groups was unknown, but this combined harvesting effort may be the cause for the observed decline.

The distance traveled by $H$. ocellatum between recaptures was highly variable and did not reveal any patterns of habitat use. Sharks did not appear to remain resident within a single coral head or specific region over the short or long term. Unlike other shark species that show predictable movement patterns over time (e.g., Morrissey and Gruber 1993, Heupel et al. 2004), H. ocellatum appeared to move randomly within the study site. Straight-line measures did not provide accurate movement data, but they did allow the minimum distance traveled to be determined. These distances, although within the study site boundaries due to the sampling methodology, lacked any discrete pattern. Randomness of movement within the study site was also supported by the lack of a relationship between the distance traveled and the number of days at liberty. Although most sharks moved only short distances, longer distances traveled by $H$. ocellatum indicate that they could easily move out of the study site. Undoubtedly, some emigration and immigration occurred during the course of the study.

Examination of population estimators revealed that the best closed population models for this population were the Chao estimators, which is consistent with the observation that these models function best when recapture rates are relatively low (Otis et al. 1978). Although the recapture rates in this study were high for a shark population (Kohler and Turner 2001), they were still low in statistical terms. The top ranking of the time-specific and individual capture probability model suggests that catchability of individuals was consistent and that the changes in the population structure at the end of the study (periods 10 
and 11) were accounted for by adjusting the time-specific capture probability. Open population estimators showed a large amount of variability among the models. Two of the Jolly models provided similar estimates of around 500 sharks within the study site. However, the Jolly $\mathrm{A}^{\prime}$ model estimate of 1,900 sharks was similar to those calculated by the closed population estimators and had confidence intervals that overlapped those of closed models. This may be because the Jolly $\mathrm{A}^{\prime}$ model did not allow for immigration into the population and therefore performed similarly to closed models.

Open population models are better suited for use with longer-term studies because their assumptions can take the movement of individuals into and out of the population into account. Although the data collected here are from a long time series, they are for a population of animals that is not known to make extensive migrations. Thus based on the biology of this species it seems reasonable to treat these data as though from a closed population based on the limited mobility of $H$. ocellatum. It was for this reason that both open and closed population models were used and compared. However, mark-recapture data indicated that individuals were able to move along the reef platform (and so out of the study site) even if they did not migrate among reefs. This suggests that some individuals would likely have moved into/out of the study site, although the number of individuals doing so may have been low. This results in a "partially open" population structure. Due to the long-term nature of the study and the fact that at least a portion of the population moved into or out of the site the open population estimators were believed to provide a more realistic representation of the population in this study. The ability of these models to account for immigration/emigration accounted for this movement along the reef that closed models (and Jolly A') could not. In addition, the study site was small in relation to the reef platform and sharks could move along Heron Island Reef. Based on this information, and the assumptions of the Jolly $\mathrm{A}^{\prime}$ model, it was therefore concluded that open models Jolly A and D provided the best population estimates for the study site (approximately 500 individuals). However, due to limited exchange of individuals in the study site closed models may provide a representation of the larger reef population that moved into and out of the study area.

Population estimates calculated here indicate that $H$. ocellatum is relatively abundant on reef flats and therefore is likely to be an important predator of invertebrates in the reef flat environment (Heupel and Bennett 1998). Knowledge of the abundance and diet of this species reveals that $H$. ocellatum may play an important role in structuring reef flat communities on the Great Barrier Reef. However, collection of individuals from a small region may have impacts on the composition of the resident population and should be considered in scientific management of this species. The population estimates calculated here are some of the first data concerning a benthic, reef-dwelling elasmobranch and reveal that mark-recapture data can be used to produce reliable population estimates. The fact that benthic species often have limited movements provides a novel opportunity to study population dynamics and examine population estimates based on open and closed models. Regardless of its limitations, this study provides a basis for comparison and extrapolation to other benthic reefdwelling sharks.

\section{ACKNOWLEDGMENTS}

We thank the staff at Heron Island Research Station, K. Townsend, T. Hollis, S. Bennett, and $T$. Turner for their help throughout this research and to C. A. Simpfendorfer for his comments on the manuscript.

\section{Literature Cited}

Begon, M. 1979. Investigating animal abundance: Capture-recapture for biologists. Edward Arnold Publishers Ltd., London.

Casey, J. G., and N. E. Kohler. 1992. Tagging studies on the shortfin mako shark Isurus oxyrinchus in the western North Atlantic. Aust. J. Mar. Freshwater Res. $43: 45-60$. 
Casey, J. G., H. L. Pratt, and C. E. Stillwell. 1985. Age and growth of the sandbar shark (Carcharbinus plumbeus) from the western North Atlantic. Can. J. Fish. Aquat. Sci. 42:963-975.

Compagno, L. J. V. 1990. Alternative lifehistory styles of cartilaginous fishes in time and space. Environ. Biol. Fish. 28:33-75.

Fitz, H. C., and R. G. Weigert. 1992. Local population dynamics of estuarine blue crabs: Abundance, recruitment and loss. Mar. Ecol. Prog. Ser. 87:23-40.

Goldberg, J., and C. Wilkinson. 2004. Global threats to coral reefs: Coral bleaching, global climate change, disease, predator plagues, and invasive species. Pages 67-92 in C. Wilkinson, ed. Status of coral reefs of the world: 2004. Australian Institute of Marine Science, Townsville.

Heupel, M. R., and M. B. Bennett. 1997. Histology of dart tag insertion sites in the epaulette shark, Hemiscyllium ocellatum (Bonnaterre) (Elasmobranchii: Hemiscyllidae). J. Fish Biol. 50:1034-1041.

. 1998. Observations on the diet and

feeding habits of the epaulette shark, Hemiscyllium ocellatum (Bonnaterre), on Heron Island Reef, Great Barrier Reef, Australia. Mar. Freshwater Res. 49:753-756.

Heupel, M. R., J. M. Whittier, and M. B. Bennett. 1999. Plasma steroid hormone profiles and reproductive biology of the epaulette shark, Hemiscyllium ocellatum. J. Exp. Zool. (Endocrinol. Suppl.) 284:586594.

Heupel, M. R., C. A. Simpfendorfer, and R. E. Hueter. 2004. Estimation of shark home ranges using passive monitoring techniques. Environ. Biol. Fish. 71:135142.

Kohler, N. E., and P. A. Turner. 2001. Shark tagging: A review of conventional methods and studies. Environ. Biol. Fish. 60:191223.

Krebs, C. J. 1989. Ecological methodology. Harper and Row, New York.

Lebreton, J.-D., K. P. Burnham, J. Colbert, and D. R. Anderson. 1992. Modelling survival and testing biological hypotheses using marked animals: A unified approach with case studies. Ecol. Monogr. 62:67118.

McManus, J. W. 1997. Tropical marine fisheries and the future of coral reefs: A brief review with emphasis on Southeast Asia. Coral Reefs 16:121-127.

Morrissey, J. F., and S. H. Gruber. 1993. Home range of juvenile lemon sharks, Negaprion brevirostris. Copeia 1993:425434.

Olsen, A. M. 1953. Tagging of school shark, Galeorbinus australis (Macleay) (Carcharhinidae), in south-eastern Australian waters. Aust. J. Mar. Freshwater Res. 4:95-109.

Otis, D. L., K. P. Burnham, G. C. White, and D. R. Anderson. 1978. Statistical inference from capture data based on closed animal populations. Wildl. Soc. Monogr. 62.

Pollock, K. H., J. D. Nichols, C. Brownie, and J. E. Hines. 1990. Statistical inference for capture-recapture experiments. Wildl. Soc. Monogr. 107.

Souter, D. W., and O. Linden. 2000. The health and future of coral reef systems. Ocean Coast. Manage. 43:657-688.

Standora, E. A., and D. R. Nelson. 1977. A telemetric study of the behaviour of free-swimming angel sharks Squatina californica. Bull. South. Calif. Acad. Sci. 76:193-201.

Stevens, J. D. 1990. Further results from a tagging study of pelagic sharks in the north-east Atlantic. J. Mar. Biol. Assoc. U.K. 70:707-720.

Szmant, A. M. 2002. Nutrient enrichment on coral reefs: Is it a major cause of coral reef decline? Estuaries 25:743-766.

White, G. C., and K. P. Burnham. 1999. Program MARK: Survival estimation from populations of marked animals. Bird Study 46 (Supplement): 120-138.

White, G. C., K. P. Burnham, D. L. Otis, and D. R. Anderson. 1978. Users manual for program Capture. Utah State University Press, Logan. 